\title{
The Ontogeny of Agonistic Behavior and the Onset of Sexual Maturation in the Paradise Fish, Macropodus opercularis (Linnaeus) ${ }^{1}$
}

\author{
ROGER E. DAVIS and JEFFREY KASSEL
}

\author{
Mental Health Research Institute and Neuroscience Laboratory, \\ The University of Michigan, Ann Arbor, Michigan 48104
}

Fish 20-100 days of age were observed in brief conflicts with a stimulus fish of similar size and age. Four stages of behavior development were identified, based on quantitative changes in behavior which occurred with increasing age. Relatively little aggressive behavior occurs in the larval stage which includes fish up to about 40 days of age. Juveniles, age 40-70 days, approach, chase, and attack each other much more than do the larva. In the adolescent stage, 70-100 days of age, the incidence of species typical displays increases paralleling the onset of puberal changes in the testis and ovary. No sex differences in behavior were seen in fish up to 100 days of age. Among adult fish of unknown age males performed lateral threat displays more frequently than females as has been previously reported.

Previous investigations in paradise fish (Macropodus opercularis) ${ }^{2}$ indicate that males and females behave differently in social conflicts. For example, Southwick and Ward (1968) report that attacks occur sooner in encounters between females than in inter-male encounters, and that females may attack more intensively than males. Davis, Harris and Shelby (1974) found that in 5-10 min encounters males performed threat displays more frequently than did females. In addition, mirror image stimuli were stronger positive reinforcers in males. The sexes show qualitatively similar threat displays, patterns of attack, and submissive postures (Forselius, 1957; Ward, 1967; Hall, 1968; Southwick and Ward, 1968; Machemer, 1970). This investigation was to examine the chronology of development in males and females of a selected number of social behaviors. One goal was to determine

${ }^{1}$ Supported in part by PHS Research Development Award K2-MH-22,183 (R.E.D.). We thank Jan Glowaky and Larry Cox for their assistance in developing experimental procedures, and Gertrude Calloway for preparing the histological sections.

${ }^{2}$ Suborder, Anabantoidei; family, Belontiidae, subfamily, Macropodinae. 
whether fish which are reared in small laboratory populations show sex differences in agonistic behavior early in development. We also sought to establish the age at which individuals begin to show puberal changes in behavior and in gonad structure preparatory to investigation of influence of social experience and sex hormones on the ontogeny of agonistic behavior.

\section{METHOD}

\section{Subjects}

One hundred and thirteen subadult $M$. opercularis, ranging in age from 20-100 days, bred from laboratory stock and raised in the laboratory were used. In addition, ten adult subjects were obtained from Gossington Tropical Fisheries, Del Ray Beach, FL. The adults were from a population which was reared and kept for breeding in the field, in large concrete tanks. The individuals were estimated to be from 4-12 mo of age.

\section{Apparatus}

Breeding and rearing tanks in the laboratory were heavily planted 57 liter $(30 \times 61 \times 31 \mathrm{~cm})$ and 75 liter $(31 \times 76 \times 32 \mathrm{~cm})$ aquaria. Water temperatures were $25-26^{\circ} \mathrm{C}$ and a daily cycle of $14 \mathrm{hr}$ of light and $10 \mathrm{hr}$ of darkness was maintained. Isolation tanks for subadults were clear plastic tanks, $13 \times 18 \times 9 \mathrm{~cm}$, which contained 1.8 liter of water. Adults were isolated in 9.5 liter $(15 \times 30 \times 20 \mathrm{~cm})$ glass aquaria. Three sides of the tanks were covered with white paper. Stimulus fish were kept in the stock rooms and could see human traffic through the front wall of the isolation tank. Experimental fish were kept in a separate room; they were disturbed only during feeding and behavior trials.

\section{Procedure}

Subadults were reared from embryos which were collected from nests and kept in small tanks until they hatched. M. opercularis hatches in 30-40 hr following fertilization (Tomita and Tuge, 1938). On Day 5, post-hatching, the free-swimming fish were transferred to rearing tanks in groups of 50-75 per tank. The developing young were fed brine shrimp nauplii, supplemented by dry Tetramin staple and conditioning food. Fish older than 40 days also received frozen adult brine shrimp. Social behavior was observed in 9 age groups of subadults and a group of adults. The subadults were 20,30,40,50, $60,70,80,90$ and 100 days of age at the start of the 7-day test period. Fish from any one brood were assigned to 1-4 different age groups, and each group 
consisted of at least nine individuals from two or more broods. The adult group consisted of five males and five females. At the start of the test period, the subject was placed in the isolation tank for 3 days. On each of the following 4 days, a stimulus fish was introduced into the tank for a $5 \mathrm{~min}$ trial. The stimulus fish was approximately the same age and size as the subject and was previously isolated in a separate tank. The $5 \mathrm{~min}$ trial was started when the fish moved to within one body length of each other. The following behavior patterns of the subjects were recorded: Approach consisted of the movement of one fish to within a body length of the other, in the absence of any immediate previous interaction. Lateral display was recorded as the full extension of the anal, dorsal and caudal fins. Frontal display was defined as the extension of the opercula as the subject faced the intruder. Quiver was a brief spasmodic vibration of the whole body. Sigmoid was a lateral curving of the body into an S-shape. Sigmoid postures occurring with lateral and frontal displays, were not counted. Curl was recorded as a lateral curving of the body into a J-shape. Circle was defined as the movement of two fish in the anti-parallel position about a vertical axis in a circular pattern. A marked increase in the intensity of the subject's skin colors during a trial was recorded as Darken. Chase was recorded each time the subject followed the withdrawing stimulus fish. Attack consisted of a quick thrust against the head or flank of the opponent. We did not distinquish between butting and biting attack. Responses were registered with a Esterline Angus operations recorder. Following the $5 \mathrm{~min}$ trial, the stimulus fish was again isolated. Fish were fed daily 15-30 min after the trial. In the 4 trials, each subject was paired with at least two different stimulus fish and no subject encountered the same fish on successive days.

\section{Histology}

Immediately following the last trial the fish was killed in ice water, measured, and fixed in 10\% neutral formalin preparatory to embedding in paraffin. Serial, parasaggital sections $8 \mu \mathrm{m}$ thick were cut from the abdomen. Representative sections were stained with hemotoxylin and eosin to identify the sex and the state of development of the gonad. The ovary and testes differentiate from an indifferent gonad between Day 20 and 25 (Schwier, 1939). Gross maturational changes in the testes include the formation of seminiferous alveoli and the onset of spermatogenesis (Nelson, 1953). Several sections of testes from each male were examined to determine whether these processes had begun. In females, the occurrence of stage I, II, and III primary oocytes was used to evaluate the state of maturation of the ovary (Saundararaj and Segal, 1970). Stage I oocytes were identified as those ranging from $5-60 \mu$ in diameter. In addition, the nucleus is relatively large and contains few to many nucleoli, and the cytoplasm is intensely basophilic. 
Stage II oocytes are larger, ranging from $60-160 \mu$, and the cytoplasm is only moderately basophilic. The cytoplasm also shows distinct cortical vacuoles signifying the onset of yolk formation. In stage III, the oocyte is $160-500 \mu$ in diameter and it is filled with yolk which imparts a characteristic coarse, granular appearance to the cytoplasm.

\section{RESULTS}

Social behavior in fish less than 70 days old consisted mainly of approach, curl, circle, chase, and attack (Fig. 1). During this period of development curl and circle declined in frequency while chase and attack

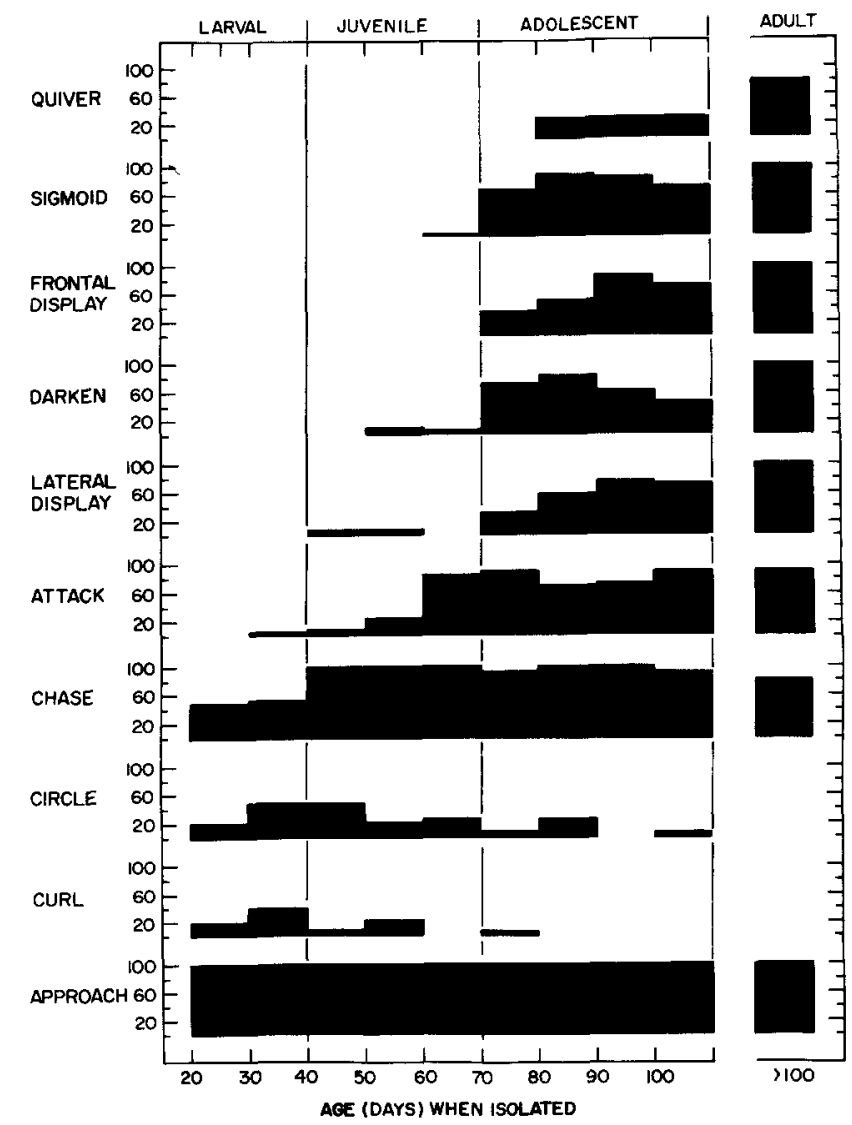

Fig. 1. The chronology of development plotted as the percentage of fish in each age group which were seen to perform the response at least once during the 4 successive daily trials. The fish were isolated for 3 days prior to the first trial. The exact age of the adults was uncertain. 
became more frequent with increasing age. Fish older than 70 days showed increased frequencies of lateral and frontal display, darken, and sigmoid. These behaviors were seen only rarely or not at all in younger fish. Quiver, the last of the responses to emerge, was seen in Day 80 and older fish.

A one-way analysis of variance indicates significant age effects on the frequency of each behavior except circle (Table 1). Examination of the data in Fig. 1 and Table 1 suggested that there were four ontogenetic ages which were designated as larval, (Day 20 and Day 30), juvenile (Day 40 to Day 60), adolescent (Day 70 to Day 100) and adult (older than 100 days). The data for groups within each ontogenetic stage were combined (Table 2). Scheffe' simultaneous $t$-tests reveal a higher frequency of approach $(t=5.14$, $P<0.001)$ and chase $(t=6.04, P<0.001)$ in juveniles than in larvae. Larvae showed curl more frequently than juveniles $(t=2.38, P<0.02)$. Compared with juveniles, adolescents showed a higher frequency of approach $(t=4.9$, $P<0.001)$, chase $(t=5.04, P<0.001)$, attack $(t=2.70, P<0.001)$, lateral display $(t=3.09, P<0.001)$, frontal display $(t=3.82, P<0.001)$, darken $(t=6.4, P<0.001)$, sigmoid $(t=4.77, P<0.001)$ and quiver $(t=2.11$, $P<0.05)$, and a lower frequency of circle $(t=-2.04, P<0.05)$. Adults showed a lower frequency of approach $(t=-5.60, P<0.001)$ and chase $(t=$ $-4.13, P<0.001)$, and a higher frequency of lateral display $(t=11.27$,

\section{TABLE 1}

The Mean Body Length, and the Mean Frequency of Various Behaviors During All Four of the 5-Min Encounters, in Fish of Increasing Chronological Age

\begin{tabular}{|c|c|c|c|c|c|c|c|c|c|c|c|}
\hline Age (days) & 20 & 30 & 40 & 50 & 60 & 70 & 80 & 90 & 100 & $>100$ & \\
\hline Sample $N$ & 10 & 26 & 10 & 9 & 11 & 11 & 12 & 13 & 11 & 10 & $F$ value \\
\hline $\begin{array}{l}\text { Body length } \\
\text { (mm) }\end{array}$ & 7.9 & 9.0 & 13.2 & 13.6 & 16.8 & 19.9 & 22.1 & 27.7 & 27.6 & 38.4 & $91.4^{a}$ \\
\hline Approach & 6.9 & 7.6 & 13.3 & 15.6 & 16.7 & 19.4 & 19.7 & 26.0 & 24.1 & 10.5 & 15.9 \\
\hline Curl & 0.5 & 0.8 & 0.4 & 0.3 & 0 & 0.1 & 0. & 0. & 0. & 0. & $2.2^{b}$ \\
\hline Circle & 0.4 & 0.9 & 1.1 & 0.8 & 0.5 & 0.1 & 0.6 & 0. & 0.4 & 0 . & $1.5^{c}$ \\
\hline Chase & 1.3 & 1.7 & 12.0 & 7.7 & 26.8 & 25.4 & 19.0 & 24.4 & 21.6 & 9.7 & 16.0 \\
\hline Attack & 0 & 0.1 & 1.6 & 1.6 & 19.4 & 45.2 & 9.8 & 19.0 & 10.3 & 8.9 & 6.5 \\
\hline Lateral & 0. & 0 & 0.1 & 0.8 & 0. & 5.0 & 13.3 & 11.8 & 1.5 & 54.0 & 20.9 \\
\hline Frontal & 0. & 0. & 0. & 0 . & 0 . & 2.0 & 4.7 & 5.9 & 5.1 & 28.9 & 22.7 \\
\hline Darken & 0. & 0 & 0. & 0.1 & 0.1 & 1.5 & 1.9 & 2.0 & 1.2 & 3.5 & 13.3 \\
\hline Sigmoid & 0. & 0. & 0. & 0 . & 0. & 7.3 & 4.3 & 12.6 & 3.9 & 12.8 & 7.6 \\
\hline Quiver & 0 & 0. & 0. & 0. & 0. & 0. & 3.4 & 1.9 & 0.5 & 6.1 & 4.4 \\
\hline
\end{tabular}

$a_{F}>3.6, P<0.001$.

$b_{P}<0.03$.

${ }^{c} P>0.05$. 
DAVIS AND KASSEL

TABLE 2

The Mean Body Length, and the Mean Frequency of Behaviors in the Four Encounters, in Fish of Different Ontogenetic Stages

\begin{tabular}{lcccc}
\hline & Larval & Juvenile & Adolescent & Adult \\
\cline { 2 - 5 } Sample $N$ & 36 & 30 & 47 & 10 \\
\cline { 2 - 5 } Sex ratio M:F & $15: 21$ & $17: 13$ & $24: 23$ & $5: 5$ \\
Body length (mm) & 8.7 & 14.7 & 24.4 & 38.4 \\
\hline Approach & & & & 10.5 \\
Curl & 7.4 & 15.2 & 22.3 & 0. \\
Circle & 0.7 & 0.2 & 0.0 & 0.3 \\
Chase & 0.8 & 0.8 & 0.3 & 9.7 \\
Attack & 1.6 & 16.1 & 22.1 & 8.9 \\
Lateral & 0.1 & 8.1 & 18.6 & 5.0 \\
Frontal & 0. & 0.3 & 8.2 & 3.5 \\
Darken & 0. & 0. & 1.7 & 6.8 \\
Sigmoid & 0. & 0. & 7.2 & 6.1 \\
Quiver & 0. & 0. & 1.5 & \\
\hline
\end{tabular}

$P<0.001)$, frontal display $(t=11.67, P<0.001)$, darken $(t=4.62$, $P<0.001)$, sigmoid $(t=2.27, P<0.05)$ and quiver $(t=4.07, P<0.001)$ than adolescents (Table 2).

Subadult males and females showed no significant differences in the frequency of the various behaviors. Adult males, however, showed more lateral display $(\bar{x}=67.2)$ than adult females $(\bar{x}=40.8 ; t=2.61, P<0.05)$.

The frequencies of certain behaviors varied with body length. In the larvae, chase increased with body length of $(r=0.50, P<0.01)$. In the juveniles, approach and chase increased $(r=0.51,0.48, P<0.01)$ and circle decreased $(r=-0.47, P<0.01)$ in frequency with body length. Lateral display and quiver increased with body length in the adolescents $(r=0.45$, for both responses, $P<0.01$ ). Body length and behavior were not significantly correlated in the adults.

Seminiferous alveoli and spermatogenetic activity were seen in sections of the testes in $80 \%$ of the Day 70 males and in $100 \%$ of the older males but in none of the Day 20-60 males. Every female showed stage I oocytes. Stage II oocytes were first seen in Day 70 and stage III oocytes in Day 90 fish. Stage II oocytes were present in 25\% of the Day 70 females, $80 \%$ of the Day 80 and the Day 90 females, and all of the Day 100 and older females. Stage III oocytes were present in 50\% of the Day 90 females, $60 \%$ of the Day 100 females and all of the adults. 


\section{DISCUSSION}

The onset of adolescence was surprisingly distinct. It was clearly represented in differences in behavior and gonad histology between Day 60 and 70 fish. Lateral and frontal threat display, quiver, sigmoid and darken were common units of behavior following Day 70 but not before (Table 1). Gonad maturation was evident in increasing numbers of males and females following Day 70. Puberal changes in behavior and in the gonads thus appear to begin between 60 and 70 days of age.

The age of sexual maturity can not be determined from this experiment, and the transition between adolescence and adulthood remains to be established. Yolk laden (stage III), primary oocytes were present in over half of the Day 100 females, and fish in our laboratory have successfully reproduced at 90 days of age. Thus, some of the older adolescents might have spawned, if a mating test had been carried out. The duration of the behavior trials was specifically limited to a period of minutes to reduce the chances that a subject and stimulus fish of opposite sex would engage in courtship which could result in reduced aggressive behavior. Machemer (1971) employed a similar procedure in measuring aggression in $M$. opercularis. In the adult group, the subjects encountered male and female stimulus fish in alternate trials. In the subadult groups, the sex of the stimulus was not determined. Since the sexes occur with nearly equal frequencies (e.g., Table 2), we assume that most of the subadult subjects also encountered both male and female stimuli. The effects of the sex of the intruder on the subjects response at different stages of development remains to be investigated. Forselius (1957) reported that $M$. opercularis is sexually mature at approximately 6 mo. Our limited data on sexual maturation can not account for the discrepancy. In addition to hereditary differences, which conceivably could exist between stocks of this domesticated fish, the age of sexual maturity might also vary with ecological factors early in development, in particular those factors which influence growth rate and social experience (Shaw, 1962).

Davis et al. (1974) found that among adult, field-grown fish the males show higher frequencies of lateral display than females. This result is confirmed by the present experiment. We anticipated that the developmental origin of this sex difference would be detected in the ontogenetic series of laboratory-reared fish but it was not. Through 100 days of age, the sexes showed similar frequencies of each of the motor patterns. Our impression is that placing the stimulus fish in the subject's tank results in low frequencies of threat display in adolescent subjects. The stimulus fish tended to be submissive and avoid the subject and thus gave the subject little opportunity to perform a threat display. Thus the test procedure may not be sensitive to an emerging sex difference in lateral display frequency.

The four stages of behavior development, which are based on quantita- 
tive changes in behavior with increasing age, provide a useful, tentative framework for future research in this species. The larval stage, Day 20 and 30 fish, is characterized by a low frequency of encounters between individuals. Younger fish appear to show even less social behavior and hence they were excluded from the experiment. Juveniles, Day 40, 50 and 60 fish, are distinctly more active in social encounters than are larvae but they seldom perform the ritualized displays which emerge in the adolescent stage, Day 70 , 80,90 and 100 fish. The frequency of attack, however, increased in the late juvenile stage reaching levels similar to those shown by adolescents. Thus attack behavior is well established in development prior to the emergence of threat displays. The juvenile resembles the adult in body shape and skin color more than does the larvae. Metamorphosis in $M$. opercularis is gradual and indistinct, as it is in many teleosts (Blaxter, 1969), and external morphological changes continue to adulthood. Differentiation of the species typical, forked caudal fin, for example, begins during the juvenile stage and is still incomplete in fish 100 days of age.

The development of fish social behavior has not been extensively investigated. The development of schooling in Menidia menidia and Menidia beryllina, and of sexual behavior in Xiphophorous maculatus have been described (Shaw, 1960, 1961, 1962). The emergence of aggressive behavior prior to sexual maturity has been reported in various fishes (Rasa, 1971; Gibson, 1968; Farwell and Green, 1974). Ohm (1958, 1964) described the development of agonistic behavior in two cichlid fishes, Aequidens portalegrensis and $A$. latifrons. Chase and lateral display emerged in 20 days following fertilization in $A$. portalegrensis and 40 days in $A$. latifrons. The ritual fighting behavior which is seen in the adult was well established in $3-$ to 4-mo old fish which were described as being sexually immature. In another cichlid, Etroplus maculatus, Wyman and Ward (1973) report that adult agonistic behavior patterns appear to be fully developed prior to 100 days of age, and approximately 3 mo before sexual maturity. It is difficult to compare the results of investigations relating sexual maturity and the development of agonistic behavior when morphological, or non-behavioral, indexes of maturity are lacking. The development of agonistic behaviors prior to the time that the individuals are functionally reproductive does not necessarily indicate that the behaviors are independent of sexual differentiation. On the contrary, it seems likely to us that agonistic behavior develops as a part of the process of sexual differentiation, and that the behaviors depend on gonadal and pituitary changes which are responsible for sexual maturation. Investigations of the chronology of behavior development may provide insights into the adaptive significance of agonistic behavior and into the underlying physiological mechanisms. 


\section{REFERENCES}

Blaxter, J. H. S. (1969). Development: Eggs and larvae. In W. S. Hoar and D. J. Randall (Eds.), "Fish Physiology," Volume III, pp. 177-252. New York: Academic Press.

Davis, R. E., Harris, C., and Shelby, J. (1974). Sex differences in aggressivity and the effects of social isolation in the anabantoid fish, Macropodus opercularis. Behav. Biol. 11, 497-509.

Forselius, S. (1957). Studies on anabantoid fishes. Part I. Zool. Bidrag. fran Uppsala 32, 94-301 (see p. 121).

Farwell, M. K., and Green, J. M. (1974). Agonistic behavior of juvenile Stichaeus punctatus (Pisces: Stichaeidae). Can. J. Zool. 51, 449-456.

Gibson, R. N. (1968). The agonistic behavior of juvenile Blennius pholis L. (Teleostei). Behaviour 30, 192-218.

Hall, D. D. (1968). A qualitative analysis of courtship and reproductive behavior in the paradise fish, Macropodus opercularis (Linnaeus). Z. Tierpsychol. 25, 834-842.

Machemer, L. (1970). Qualitative and quantitative Verhaltensbeobachtungen an Paradiesfisch-ठర;; Macropodus opercularis L. (Anabantidae, Teleostei). Z. Tierpsychol. 27, 563-590.

Machemer, L. (1971). Synergistische Wirkung von Säuger-Prolacktin und Androgen beim Schaumnestbau des Paradiesfisches, Macropodus opercularis L. (Anabantidae). $Z$. Tierpsychol. 28, 33-53.

Nelson, O. E. (1953). "Comparative Embryology of the Vertebrates," p. 982. New York: Blakiston Co.

Ohm, D. (1958). Die ontogenetische Entwicklung des Kampfverhaltens Adequidens portalegrensis Hensel und A. latifrons Steindachner (Cichlidae). Verh. Deut. Zool. Geo. Frankfurt 1958, 181-194.

Ohm, D. (1964). Die entwicklung des kommentkampfverhaltens bei jungcichliden. $Z$. Tierpsychol. 21, 308-325.

Rasa, O. A. E. (1971). "Appetence for Aggression in Juvenile Damsel Fish," p. 70. Berlin: Paul Parey.

Schwier, H. (1939). Geschlechtsbestimmung und differenzierung bei Macropodus opercularis, concolor, chinesis und deren Artbastarden. Z. Indukt. Abstramm. Verebungsl. 77, 291-335.

Shaw, E. (1960). The development of schooling behavior in fishes. Physiol. Zool. 33, 79-86.

Shaw, E. (1961). The development of schooling in fishes. II. Physiol. Zool. 34, 263-272.

Shaw, E. (1962). Environmental conditions and the appearance of sexual behavior in the platyfish. In E. Bliss (Ed.), "Roots of Behavior," pp. 123-141. New York: Harper.

Southwick, C. H., and Ward, R. W. (1968). Aggressive display in the paradise fish, Macropodus opercularis L. Turtox News 46, 57-62.

Sundararaj, B. I., and Sehgal, A. (1970). Effects of a long or increasing photoperiod on the initiation of ovarian recrudescence during the preparatory period in the catfish, Heteropneustes fossilis (Bloch). Biol. Reprod. 2, 413-424.

Tomita, G., and Tuge, H. (1938). The development of behavior of the paradise fish. $J$. Shanghai Sci. Inst. Sect. 4 3, 269-278.

Ward, R. W. (1967). Ethology of the paradise fish, Macropodus opercularis. I. Differences between domestic and wild fish. Copeia 4, 809-813.

Wyman, R. L., and Ward, J. A. (1973). The development of behavior in the cichlid fish Etropulus maculatus (Bloch). Z. Tierpsychol. 33, 461-491. 